\section{EREM 76/3}

Journal of Environmental Research, Engineering and Management Vol. 76 / No. 3 / 2020 pp. 47-61 DOI 10.5755/j01.erem.76.3.25338
Treatment of Combined Acid Black 48 and Coffee Wastewater by Low-Cost Adsorbents
Accepted after revision 2020/08

\title{
Treatment of Combined Acid Black 48 and Coffee Wastewater by Low-Cost Adsorbents
}

\author{
Abhiram Siva Prasad Pamula, Yung-Tse Hung* \\ Civil and Environmental Engineering, Cleveland State University, Cleveland, Ohio 44115 USA \\ Howard H. Paul \\ Information Systems, Cleveland State University, Cleveland, Ohio 44115 USA
}

*Corresponding author: yungtsehung@yahoo.com

Removal of synthetic dyes from wastewater is essential both from the environmental and human health point of view. A small concentration of synthetic dyes can reduce water transparency and consequently influence photosynthesis and alter aquatic ecosystems. Acid black 48 is an Azo dye that falls under the category of synthetic dyes used in the textile industry. With dyes, coffee wastewater has high chemical oxygen demand (COD) that can affect dissolved oxygen (DO) in surface waters. A mixture of wastes in surface waters creates a need to investigate the efficiency of existing treatment methods and optimize them. Adsorption using activated carbon is a conventional method used to remove dyes and heavy metals from wastewater. Industries prefer efficient and economical treatment methods to meet challenging effluent standards regarding COD, BOD, and intensity of color. The adsorption process was optimized using low-cost adsorbents in the current study, including peanut hull and onion peel, to treat a binary mixture of acid black 48 and coffee wastewater. After adsorption, microfiltration was used to remove any suspended solids from the wastewater solution. The performance of combined treatment processes for the color removal of the binary mixture was analyzed and compared using transmittance and absorbance. Treatment efficiency of adsorption using low-cost adsorbents was compared with powdered activated carbon. Apart from absorbance and transmittance, non-purgeable organic carbon (NPOC) values were analyzed to determine organic carbon removal in the combined binary wastewater. Experimental results indicated that Langmuir isotherm was the best fit for a binary mixture with an optimum dosage of $1.2 \mathrm{~g}$ using onion peel. The regression coefficient value was 0.82 , and the uptake was $58.13 \mathrm{mg}$ of binary mixture per $1 \mathrm{~g}$ of onion peel. The effective $\mathrm{pH}$ for maximum uptake of acid black 48 using onion peel for adsorption 
was 5.7. The increasing dosage of low-cost adsorbents adsorption improved in removing binary waste of dyes and coffee waste from wastewater. Adsorption using onion peel improved adsorbent performance up to $1.2 \mathrm{~g}$ dosage and steadily decreased beyond that. The adsorption capacity of onion peel was comparatively higher than the peanut hull based on the linear fit.

Keywords: dye wastewater, coffee wastewater, adsorption, microfiltration, acid black 48.

\section{Introduction}

Dyes are used in commercial, pharmaceutical, textile, cosmetic, and food industries. Synthetic production of dyes has become very significant. Over 100,000 varieties are available commercially with an annual production of $7 \times 10^{5}$ metric tons (Fu and Viraraghavan, 2001; Robinson et al., 2001). Synthetic dyes use an enormous amount of surface water for processing and pre-treatment. Textile industries primarily use a large amount of water for washing, dyeing, and leaching purposes producing wastewater (Bharti et al., 2013; Imtiazuddin et al., 2012; Sultana et al., 2013). Discharge of dye wastewater from industries can pollute surface water streams. If the dye wastewater is not treated properly before releasing to the environment, the effluent from these industries can cause determental effect onquality of receiving waters in terms of $\mathrm{pH}$, total suspended solids (TSS), total dissolved solids (TDS) and transmittance (Ahmed et al., 2012; Dey and Islam, 2015; Islam and Guha, 2013; Yaseen and Scholz, 2016).

Removing dye contaminants in wastewater using conventional wastewater treatment methods, including activated sludge and trickling filters, is not efficient. Although conventional wastewater treatment methods can be used as a pre-treatment step to remove significant organic content, they can not remove synthetic dyes from wastewater (Kornaros and Lyberatos, 2006)continuously and as a sequencing batch reactor (SBR. As untreated wastewater contains high concentration of TSS and TD, there is a high chance of environmental risk if untreated dye wastewater is released to surface water. As far as human health is concerned, reactive dyes create respiratory problems because of inhalation (Hassaan and Nemr, 2017). Inhaling dyes by humans is a potential risk in terms of health while showering. An increase in risk to both humans and the environment creates the need for treatment and makes the treatment process a priority to remove dyes from wastewater.

Some conventional wastewater treatment processes to treat dye wastewater are adsorption, coagulation, and electrochemical oxidation (Ge et al., 2012; Li et al., 2017; Lin andPeng, 1996; S. V. H. Madiraju et al., 2019; Ren et al., 2013). Adsorption is a preferred treatment method because of treatment efficiency, and simplicity. Dye manufacturing companies use the adsorption process to remove the color from wastewater. One of the significant variables that affect the dye wastewater treatment process is the adsorbent particle size (Ong et al., 2010). The adsorption process efficiency is closely related to the surface area and number of sorption sites in the adsorbent, which makes activated carbon an ideal adsorbent (Johnson et al., 2002; S. V. H. Madiraju et al., 2020). Adsorption as a treatment process is effective compared to all the other treatment processes. Still, the major disadvantage is the high investment involved in using virgin carbon and recycling cost in spent carbon usage (Alhashimi and Aktas, 2017)and its applications diversifying from its early uses as soil amendment, it is important to study the environmental impacts and economic performance of biochar in comparison to activated carbon in order to assess its value. The goal of the study was to assess, through a meta-analysis, the environmental and economic performance of biochar in comparison to activated carbon under an equivalent functional unit to adsorb heavy metals. More than 80 data points on adsorption capacity of biochar and activated carbon were identified through literature, which were statistically analyzed as part of the study. Biochar was found to have lower energy demand and global warming potential 
impact than activated carbon, where average energy demands were calculated as $6.1 \mathrm{MJ} / \mathrm{kg}$ and $97 \mathrm{MJ} / \mathrm{kg}$ and average greenhouse gas emissions calculated as $-0.9 \mathrm{~kg} \mathrm{CO} 2 \mathrm{eq} / \mathrm{kg}$ and $6.6 \mathrm{~kg}$ CO2eq $/ \mathrm{kg}$ for biochar and activated carbon, respectively. When adsorption of heavy metals were used as the functional unit during analysis, results indicate that there is typically an order of magnitude difference between the two materials, where biochar was found to have lower environmental impacts. The environmental impact resulting from long distance transportation of biochar would not overturn this conclusion. The adsorption cost of biochar was lower than activated carbon to remove chromium and zinc with a 95\% confidence. Adsorption cost for lead and copper were found to be comparable, and therefore the specific type of biochar and its price could shift results both ways. There is evidence that biochar, if engineered correctly for the task, could be at least as effective as activated carbon and at a lower cost.","container-title":"Resources, Conservation and Recycling","DOI":"10.1016/j. resconrec.2016.11.016","ISSN":"0921-3449","journalAbbreviation":"Resources, Conservation and Recycling","language":"en","page":"13-26","source":"ScienceDirect","title":"Life cycle environmental and economic performance of biochar compared with activated carbon: A meta-analysis","title-short":"Life cycle environmental and economic performance of biochar compared with activated carbon","volume":"118","author":[["family":"Alhashimi","given":"Hashim A."],\{"family":"Aktas","given":"Can $\quad$ B."\}],"issued":\{"date-pa rts":[["2017",3,1]]\}\}\}],"schema":"https://github.com/ citation-style-language/schema/raw/master/csl-citation.json"\} . Low-cost adsorbents from agricultural wastes were studied to reduce the cost involved in the sorption process to make the treatment process economical. Most of these low-cost adsorbents are readily available and are economical to use and dispose of (Weng and Pan, 2007)a waste produced from an edible oil manufacturer was investigated. Results showed that the adsorption increased with increasing MB concentration, temperature, and $\mathrm{pH}$. The adsorption equilibrium data was well fitted by multilayer adsorption isotherm. The maximum adsorption capacities for MB ranged from $0.94 \times 10-4$ to $3.41 \times 10-4 \mathrm{~mol} / \mathrm{g}$ between 5 and $45^{\circ} \mathrm{C}$. Thermodynamic parameters suggest that the adsorption is spontaneous and endothermic. We proposed a modified double exponential equation accounting both with chemical and mathematical point of view to describe the adsorption kinetic data. The increases of mass transfer and adsorption capacity were mainly attributed to the interlayer of the SAC expanding at higher temperature. An activation energy of $13.5 \mathrm{kcal} / \mathrm{Kmol}$ was determined suggesting that the adsorption involved a chemical reaction mechanism.","container-title":"Journal of Hazardous Materials","DOI":"10.1016/j.jhazmat.2006.09.097","ISSN":"0304-38 94","issue":"1","journalAbbreviation":"Journal of Hazardous Materials","language":"en","page":"355-362","source":"ScienceDirect","title":"Adsorption of a cationic dye (methylene blue. There are sufficient sorption sites in agricultural wastes that can reduce the expenses involved in using powdered activated carbon (Adegoke and Bello, 2015)these processes are effective and economic only in the case where the solute concentrations are relatively high. Most industries use dyes and pigments to color their products. The presence of dyes in effluents is a major concern due to its adverse effect on various forms of life. The discharge of dyes in the environment is a matter of concern for both toxicological and esthetical reasons. It is evident from a literature survey of about 283 recently published papers that low-cost adsorbents have demonstrated outstanding removal capabilities for dye removal and the optimal equilibrium time of various dyes with different charcoal adsorbents from agricultural residues is between 4 and $5 \mathrm{~h}$. Maximum adsorptions of acidic dyes were obtained from the solutions with $\mathrm{pH}$ 8-10. The challenges and future prospects are discussed to provide a better framework for a safer and cleaner environment.","container-title":"Water Resources and Industry","DOI":"10.1016/j.wri.2015.09.002 ","ISSN":"2212-3717","journalAbbreviation":"Water Resources and Industry","language":"en","page":"8-24","source":"ScienceDirect","title":"Dye sequestration using agricultural wastes as adsorbents","volume":"12","author":[["family":"Adegoke","given":"Kayode Adesina"\},\{"family":"Bello","given":"Olugbenga Solomon"\}],"issued":\{"date-parts":[["2015",12,1]]\}\}\}],"s chema":"https://github.com/citation-style-language/ schema/raw/master/csl-citation.json"\} . 
Despite being efficient and economical, low-cost adsorbents have problems with disposal, similar to conventional adsorbents. Landfills might not be a feasible option if there are heavy metals and other toxic compounds that are adsorbed in the adsorption process (Bekbölet et al., 1996; Shon et al., 2005; Torretta et al., 2017). Cementitious materials, which include fly ash, provide potential physical encapsulation and chemical stability to toxic waste in landfills (Kosson et al., 2002; Okoronkwo et al., 2018). Using recycled products from the cement industry is a feasible option for the safe disposal of dye adsorbed materials (Huang et al., 2017; Limbachiya et al., 2012).

In this study, low-cost adsorbents were used to remove acid black 48 combined with coffee wastewater. Some low-cost adsorbents involved in the treatment process were peanut hull and onion peel. Peanut is an important food crop and edible oil source in the world. Major countries, including China, India, and the USA, produce and export peanuts ( $Z$. Chen et al., 2017; Fletcher and Shi, 2016). Similarly, onions are primarily consumed in China and India (C. Chen et al., 2008; Gummagolmath, 2012). The abundance of peanuts and onions in the world market makes them potential low-cost adsorbents that can remove contaminants from wastewater. In this study, both peanut hull and onion peel were used to remove the binary mixture of acid black 48 with coffee waste in aqueous solution. Batch adsorption sampling was used to analyze the initial and final concentrations in wastewater (Din et al., 2009; Hameed and Ahmad, 2009; Luengo et al., 2006; S. V. H. Madiraju et al., 2018a). Equilibrium studies were performed to find the final concentration of combined dye and coffee wastewater using Beer-Lambert's law (Andorn and Bar冈Eli, 1971). The dynamic equilibrium of combined acid black 48 and coffee wastewater was studied using adsorption isotherms. Furthermore, the amount of organic carbon removed from the wastewater was assessed using NPOC (Augugliaro et al., 2004; Kirkels et al., 2014)"volume":"8","author":[\{"family":"Augugliaro","given":"V"\},\{"family":"Prevot","given":"A Bianco"\},\{"family":"Vázquez","given":"J Cáceres"\},\{"family":"Garcıa -López","given":"E"\},\{"family":"Irico","given":"A"\},\{"family":"Loddo","given":"V"\},\{"family":"Rodrıguez","given":"S Malato"\},\{"family":"Marcı","given":"G"\},\{"family":"Pal-
misano","given":"L"\},\{"family":"Pramauro","given":"Edmondo"\}],"issued":\{"date-parts":[["2004"]]\}\},"label":"page"\},\{"id":527,"uris":["http://zotero.org/ users/5167652/items/76QLE3J8"],"uri":["http://zotero.org/users/5167652/items/76QLE3J8"],"itemData":\{"id":527,"type":"article-journal","abstract":"RATIONALE Dissolved organic carbon (DOC.

\section{Materials and Methods}

Materials

The materials used in the research process are as follows:

1 Adsorbate: Acid black 48 mixed with coffee wastewater;

2 Low-cost Adsorbents: peanut hull, onion peel;

3 Reference Adsorbent: Powdered activated carbon (PAC).

The equipment used in the data collection and analysis include:

1 Weighing balance (OHAUS PA1502);

2 Spectrophotometer (Carolina \#65-3303);

3 Platform Shaker (Innova 2300);

4 TOC Analyzer (Shimadzu TOC-L).

Adsorbate

Acid black 48 is a non-dispersed, anthraquinone dye bought from Sigma-Aldrich company and was used while mixing with processed coffee waste in the water. A stock solution of acid black 48 was prepared with a concentration of $1000 \mathrm{mg} / \mathrm{L}$ and diluted when preparing the batch samples. Batch samples prepared had dye concentrations of 50,100 and $200 \mathrm{mg} / \mathrm{L}$, where the coffee concentration varied from 0 to $300 \mathrm{mg} / \mathrm{L}$. The chemical structure of acid black 48 dye is as illustrated in Fig. 1 .

\section{Low-cost adsorbents}

The low-cost adsorbents used in the treatment process include peanut hull and onion peel. Both peanuts and onions were obtained from a local store, and peels were removed. The peels obtained were washed thoroughly with tap water and air-dried for $48 \mathrm{hrs}$. The dried sorbents were ground to a fine powder and sieved through different sieve sizes such as $3.327-2.38,2.38-2.362,2.362-0.6,0.6-0.425,<0.425$ $\mathrm{mm}$. Although peanut hull was used with a different 
Fig. 1. Chemical structure of Acid black 48<smiles>Nc1ccc(Nc2ccc(N)c3c2C(=O)c2ccccc2C3=O)c2c1C(=O)c1ccccc1C2=O</smiles>

particle size as mentioned, the adsorbent dosage was maintained constant at $1 \mathrm{~g}$. Onions were washed with tap water and oven-dried for $24 \mathrm{hrs}$ and ground to a fine powder. They were sieved with $<0.425 \mathrm{~mm}$, and the dosage levels were varied from 0.4 to $2 \mathrm{~g}$.

Reference adsorbent

Powdered activated carbon (PAC) was the reference adsorbent used in the treatment process of acid black 48 combined with coffee wastewater. The manufacturer of the PAC was DARCO with grade HDC. The values obtained from the treatment process using PAC have been tabulated and used as a reference in the treatment process's comparative study.

\section{Weighing balance (OHAUS PA1502)}

The weighing balance comprises a metal base with a stainless-steel pan. It can be used for weighing, counting, and percentage weighing. An upfront level indicator was provided with this weighing scale such that users could quickly ensure that the balance is level. There were three filter modes and adjustable zero trackings that balance sensitivity to environmental disturbances. The maximum capacity of the weighing balance is $1500 \mathrm{~g}$ with readability up to significant digits of $0.01 \mathrm{~g}$. It was tared with a starting time of $1 \mathrm{sec}$ and with a stabilization time of $3 \mathrm{sec}$. The weighing balance can be operated between $10^{\circ} \mathrm{C}$ and $40^{\circ} \mathrm{C}$, and relative humidity ranges from $10 \%$ to $80 \%$, and up to $4000 \mathrm{~m}$ above sea level.

\section{Spectrophotometer}

A spectrophotometer was operated within a wavelength of units in $\mathrm{nm}$. Absorbance and transmittance of the wastewater samples were obtained from the Carolina UV-VIS spectrophotometer with an absorbance accuracy check of $\pm 2 \%$ at $1 \AA$. It accepts test tubes or square cuvette with size $10 \mathrm{~mm}$. The wavelength range of the spectrophotometer was 335-1000 $\mathrm{nm}$, with a spectral bandpass of $20 \mathrm{~nm}$. Wavelength accuracy and wavelength repeatability is $\pm 2 \mathrm{~nm}$ and $\pm 1 \mathrm{~nm}$, respectively.

\section{Platform shaker (Innova 2300)}

Vibration to the platform was provided by a triple-eccentric counterbalance drive inserted in a cast iron housing. Shaking range is between $25-500 \mathrm{rpm}$ with $2.5 \mathrm{~cm}$ orbit. Shaking speed can be increased or decreased by increments or decrements of $1 \mathrm{rpm}$. Platform size was $76 \times 46 \mathrm{~cm}$ and had a timer from 0.1 to $0.99 \mathrm{~h}$ with both audio and visual alarm systems.

\section{TOC analyzer (Shimadzu TOC-L)}

TOC-L analyzer used can combust the wastewater sample at $680^{\circ} \mathrm{C}$ by catalytic combustion. It can analyze samples with a detection limit of $4 \mu \mathrm{g} / \mathrm{L}$. This high sensitivity of detection enables this equipment to analyze both low-molecular-weight and hard-to-decompose macromolecular organic compounds. It can measure total carbon (TC), inorganic carbon (IC), total organic carbon (TOC), non-purgeable organic carbon (NPOC), purgeable organic carbon (POC), and total nitrogen (TN).

\section{Methods}

\section{Binary dye and coffee wastewater}

Stock samples were prepared by weighing $1 \mathrm{~g}$ acid black 48 on a weighing scale (OHAUS PA1502) with $\pm 0.01 \mathrm{~g}$ precision. A stock solution of dye wastewater was prepared by adding $1 \mathrm{~g}$ of dye to the 1000 $\mathrm{mL}$ of water. After preparation, it was stirred with a glass stirrer such that the dye mixes thoroughly. All the stock solution samples were covered with aluminum foil to prevent oxidation. Later, the required dye wastewater concentrations were prepared by dilution. Similarly, a coffee wastewater stock solution was prepared by weighing and mixing $1 \mathrm{~g}$ of ground coffee powder to $1000 \mathrm{~mL}$ of water. Later, the diluted 
coffee wastewater was mixed with dye wastewater to create a binary mixture of combined dye and coffee wastewater.

\section{Batch experiments and techniques}

Adsorption investigations were carried out with 50 $\mathrm{mL}$ volume and 50,100 , and $200 \mathrm{mg} / \mathrm{L}$ concentration of dye solution in centrifuge bottles. Run protocol for dye, coffee, and adsorbent concentration was developed based on trial and error, as shown in Table 1. As different concentrations of dye wastewater were prepared at 50, 100 and $200 \mathrm{mg} / \mathrm{L}$, they were designated as low, medium, and high concentrations for ease of reference (S. V. H. Madiraju et al., 2018).

Table 1. Run protocol of medium concentration of dye and coffee wastewater solution treated with onion peel

\begin{tabular}{|c|c|c|c|}
\hline $\begin{array}{l}\text { Run } \\
\text { order }\end{array}$ & $\begin{array}{l}\text { Dye concentration } \\
\text { (Medium) (mg/L) }\end{array}$ & $\begin{array}{c}\text { Adsorbent } \\
\text { concentration } \\
\text { (g) }\end{array}$ & $\begin{array}{c}\text { Coffee } \\
\text { concentration } \\
(\mathrm{mg} / \mathrm{L})\end{array}$ \\
\hline 1 & 100 & 0 & 0 \\
\hline 2 & 100 & 0 & 100 \\
\hline 3 & 100 & 0 & 150 \\
\hline 4 & 100 & 0 & 200 \\
\hline 5 & 100 & 0 & 250 \\
\hline 6 & 100 & 0 & 300 \\
\hline 7 & 100 & 0.4 & 0 \\
\hline 8 & 100 & 0.4 & 100 \\
\hline 9 & 100 & 0.4 & 150 \\
\hline 10 & 100 & 0.4 & 200 \\
\hline 11 & 100 & 0.4 & 250 \\
\hline 12 & 100 & 0.4 & 300 \\
\hline 13 & 100 & 0.8 & 0 \\
\hline 14 & 100 & 0.8 & 100 \\
\hline 15 & 100 & 0.8 & 150 \\
\hline 16 & 100 & 0.8 & 200 \\
\hline 17 & 100 & 0.8 & 250 \\
\hline 18 & 100 & 0.8 & 300 \\
\hline 19 & 100 & 1.2 & 0 \\
\hline 20 & 100 & 1.2 & 100 \\
\hline
\end{tabular}

\begin{tabular}{l|c|c|c}
\hline $\begin{array}{c}\text { Run } \\
\text { order }\end{array}$ & $\begin{array}{c}\text { Dye concentration } \\
\text { (Medium) (mg/L) }\end{array}$ & $\begin{array}{c}\text { Adsorbent } \\
\text { concentration } \\
(\mathrm{g})\end{array}$ & $\begin{array}{c}\text { Coffee } \\
\text { concentration } \\
\text { (mg/L) }\end{array}$ \\
\hline 21 & 100 & 1.2 & 150 \\
\hline 22 & 100 & 1.2 & 200 \\
\hline 23 & 100 & 1.2 & 250 \\
\hline 24 & 100 & 1.2 & 300 \\
\hline 25 & 100 & 1.6 & 0 \\
\hline 26 & 100 & 1.6 & 100 \\
\hline 27 & 100 & 1.6 & 150 \\
\hline 28 & 100 & 1.6 & 200 \\
\hline 29 & 100 & 1.6 & 250 \\
\hline 30 & 100 & 1.6 & 300 \\
\hline 31 & 100 & 2 & 0 \\
\hline 32 & 100 & 2 & 100 \\
\hline 33 & 100 & 2 & 150 \\
\hline 34 & 100 & 2 & 200 \\
\hline 35 & 100 & 2 & 300 \\
\hline 36 & 100 & 250 & \\
\hline
\end{tabular}

From the coffee stock solution, batch samples were prepared using dilution including 100, 150, 200, 250, and $300 \mathrm{mg} / \mathrm{L}$ mixed with the $50 \mathrm{~mL}$ dye solution at $100 \mathrm{rpm}$ (rapid shake) for 1 minute (slow shake) and $30 \mathrm{rpm}$ for 30 minutes at room temperature $\left(25^{\circ} \pm 2^{\circ} \mathrm{C}\right)$. Controls without adsorbent were prepared simultaneously to understand that results were obtained only from the adsorption process but not due to the walls of the centrifuge bottles. The percentage uptake of combined dye and coffee wastewater is:

$$
\text { Percentage Uptake }(\%)=\frac{C_{0}-C_{t}}{C_{0}} * 100
$$

where $C_{0}$ is the initial concentration, and $C_{t}$ is the concentration at a time $\mathrm{t}$.

The dye concentrations were analyzed using the Carolina UV-VIS spectrophotometer. All the measurements were taken at the wavelength corresponding to the maximum absorption of acid black 48 , i. e., $\lambda_{\text {max }}=663 \mathrm{~nm}$. 


\section{Results and Discussion}

The main criteria describing the performance of adsorption and microfiltration are adsorbent particle size, dosage, and non-purgeable organic carbon (NPOC) based on absorbance and transmittance. During batch experiments, peanut hull particle size was defined using sieve analysis with size ranging from 3.327 to $0.425 \mathrm{~mm}$ and dosage ranging from 0.2 to 2 g. Adsorbent dosage ranging from 0.4 to $2 \mathrm{~g}$ was used for onion peel without sieving. Apart from adsorbent size and dosage, NPOC was used to measure the performance of organic carbon removal in adsorption (using low-cost adsorbents) followed by microfiltration. The efficiency of binary mixture treatment was observed based on transmittance. For treatment performance comparison, transmittance was categorized as before treatment (BT) and after treatment (AT) with fixed dye concentration and varying coffee concentration ranging from $0,100,150,200,250$, and $300 \mathrm{mg} / \mathrm{L}$ respectively for a batch as shown in Fig. 2 to Fig. 4. Three batches were tested by categorizing dye concentration at low (50 mg/L), medium (100 mg/L), and high (200 mg/L). After comparing transmittance, isotherms were used to select and optimize the use of adsorbents in the treatment process. It was noteworthy to mention that the current treatment approach can be upscaled to the actual industrial conditions at the tertiary treatment stage.

\section{Adsorbent particle size and dosage on adsorption}

Transmittance is a parameter used to quantify the treatment of wastewater in terms of color removal. Transmittance before treatment (BT) and after treatment (AT) of a combined binary mixture of dye and coffee wastewater at varying concentrations were compared. This comparison gives a relationship between adsorbent dosage and transmittance. As shown in Figs. 2, 3, and 4, the following bar graphs with different adsorbents, including PAC, peanut hull, and onion peel show that an increase in adsorbent size and dosage improve the transmittance.

As seen in Fig. 2 binary mixture of acid black 48 dye and coffee wastewater were removed with an increase in adsorbent dosage. Being an excellent adsorbent, PAC has the highest transmittance, touching 80 to $100 \%$ with dosage levels from 0.4 to $1 \mathrm{~g}$.

Fig. 2. Comparison of transmittance with binary wastewater at $200 \mathrm{mg} / \mathrm{L}$ using PAC

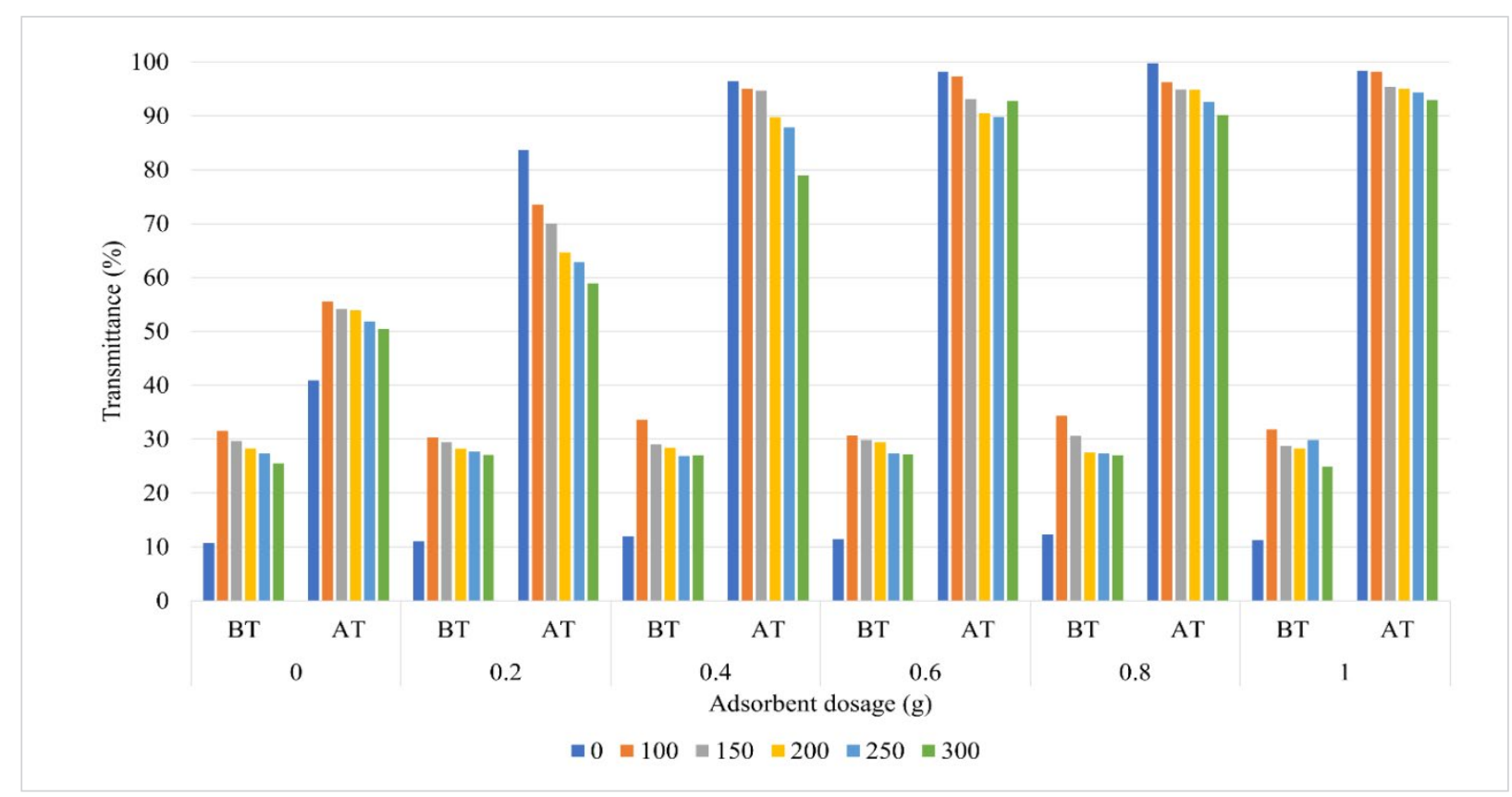


Fig. 3. Comparison of transmittance with the binary mixture at $200 \mathrm{mg} / \mathrm{L}$ using peanut hull

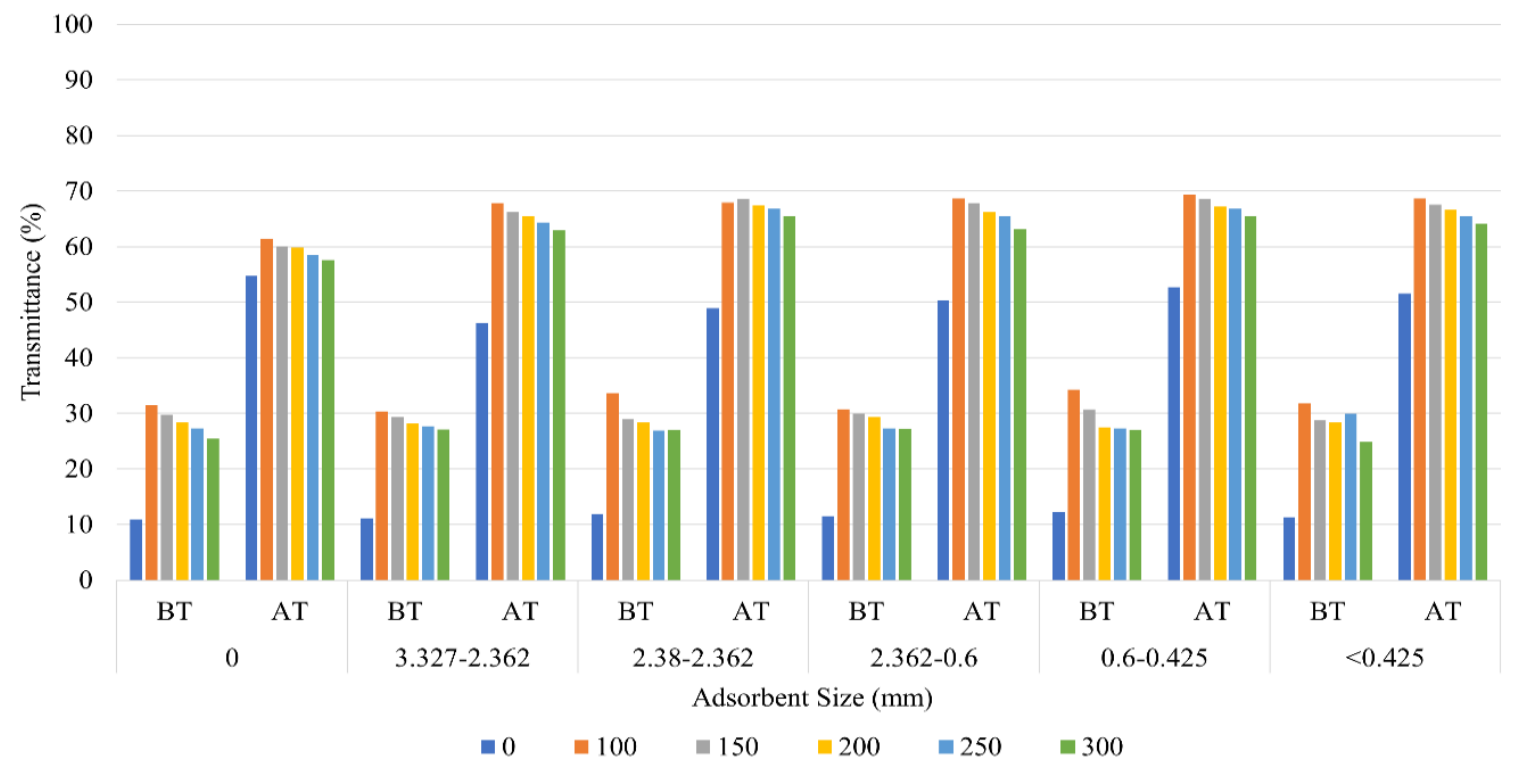

Fig. 4. Comparison of transmittance with the binary mixture at $200 \mathrm{mg} / \mathrm{L}$ using onion peel

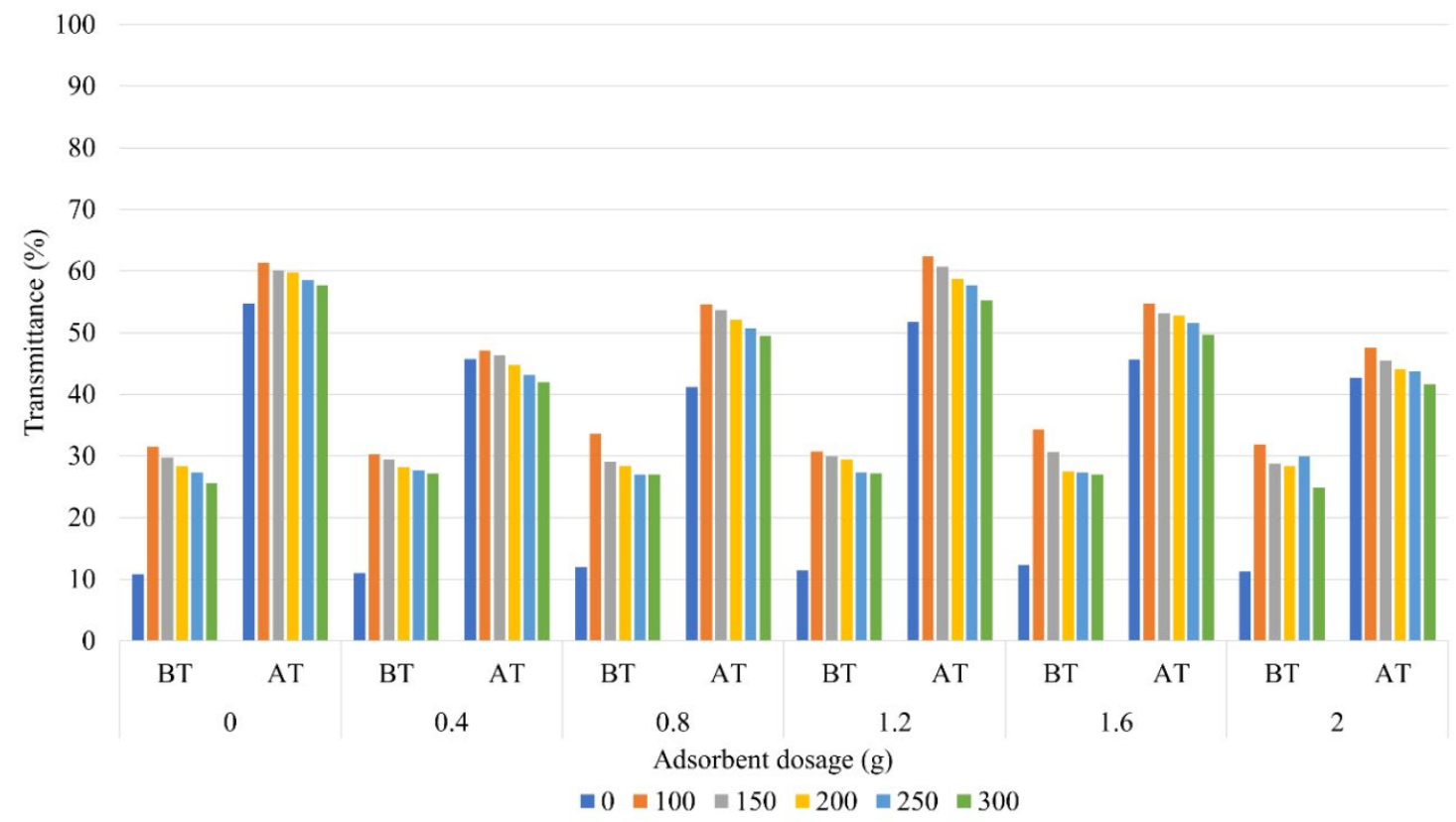


Although low-cost adsorbents do not have the potential to remove color like PAC, peanut hull at different adsorbent sizes could improve transmittance from 30 to $70 \%$ of a binary mixture of dye and coffee wastewater as illustrated in Fig. 3. Therefore, using low-cost adsorbents seems to be a good pre-treatment option, which can reduce the use of PAC in the treatment process.

Since different peanut hull sizes do not seem to affect the adsorption of combined dye and coffee waste from aqueous solution, onion peel at different concentrations were used. Based on the results, as shown in Fig. $4,1.2 \mathrm{~g}$ per $50 \mathrm{~mL}$ seems to be an optimum dosage for the binary mixture to remove color.

Onion peel at optimum dosage of $1.2 \mathrm{~g}$ seems to transmit $2.42 \%$,and $3.84 \%$ more light than peanut hull at low and medium concentration of acid black 48 , indicating better color removal in terms of transmittance. At high concentrations of acid black 48 in binary wastewater solution, peanut hull seems to adsorb better. At high concentrations, $11.21 \%$ more light was transmitted by wastewater while using peanut hull as an adsorbent, as shown in Fig. 5. Onion peel seems to be a good low-cost adsorbent when compared with peanut hull.

Fig. 5. Comparison of transmittance of acid black 48 and coffee wastewater at optimum adsorbent size and dosage

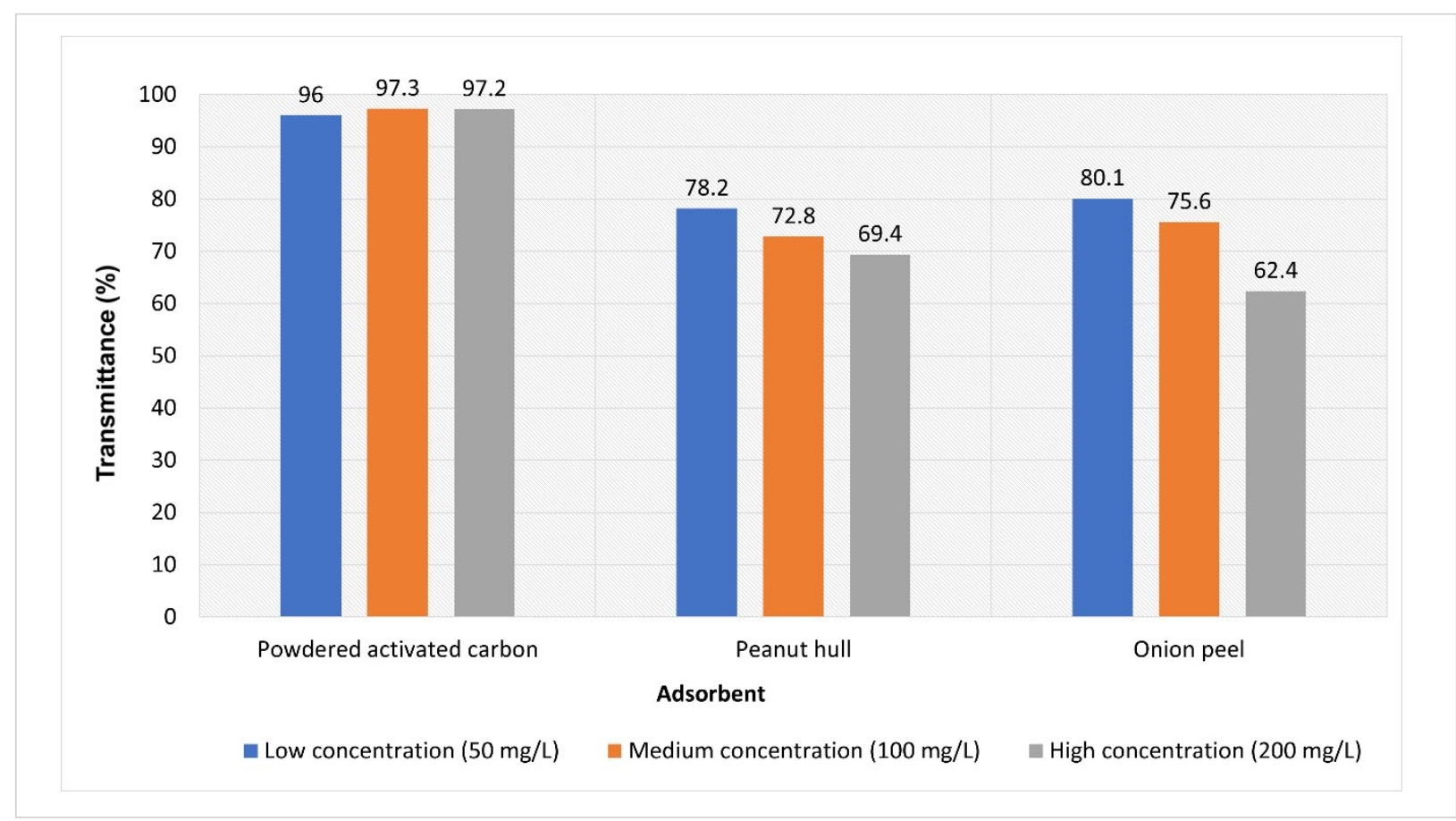

NPOC

Non-purgeable organic carbon (NPOC) is the organic carbon left and purges out the purgeable carbon using $\mathrm{HCl}$ acid. To better understand the quality of treatment using low-cost adsorbents in terms of organic carbon, the NPOC parameter was used. The current study shows the amount of coffee that was removed from the binary mix of acid black 48 and coffee wastewater using low-cost adsorbents. NPOC for a high concentration of acid black 48 at $200 \mathrm{mg} / \mathrm{L}$ with increasing coffee concentration from 100 to $300 \mathrm{mg} / \mathrm{L}$ was shown in the comparative plot of Fig. 6.

From Fig. 6, it can be observed that activated carbon best removes the organic carbon better than the low-cost adsorbents. While comparing low-cost adsorbents, onion peel was better than peanut hull in removing organic carbon. Therefore, onion peel can remove organic carbon from binary wastewater. 
Fig. 6. Comparison of NPOC at $200 \mathrm{mg} / \mathrm{L}$ acid black 48 with increasing coffee concentration

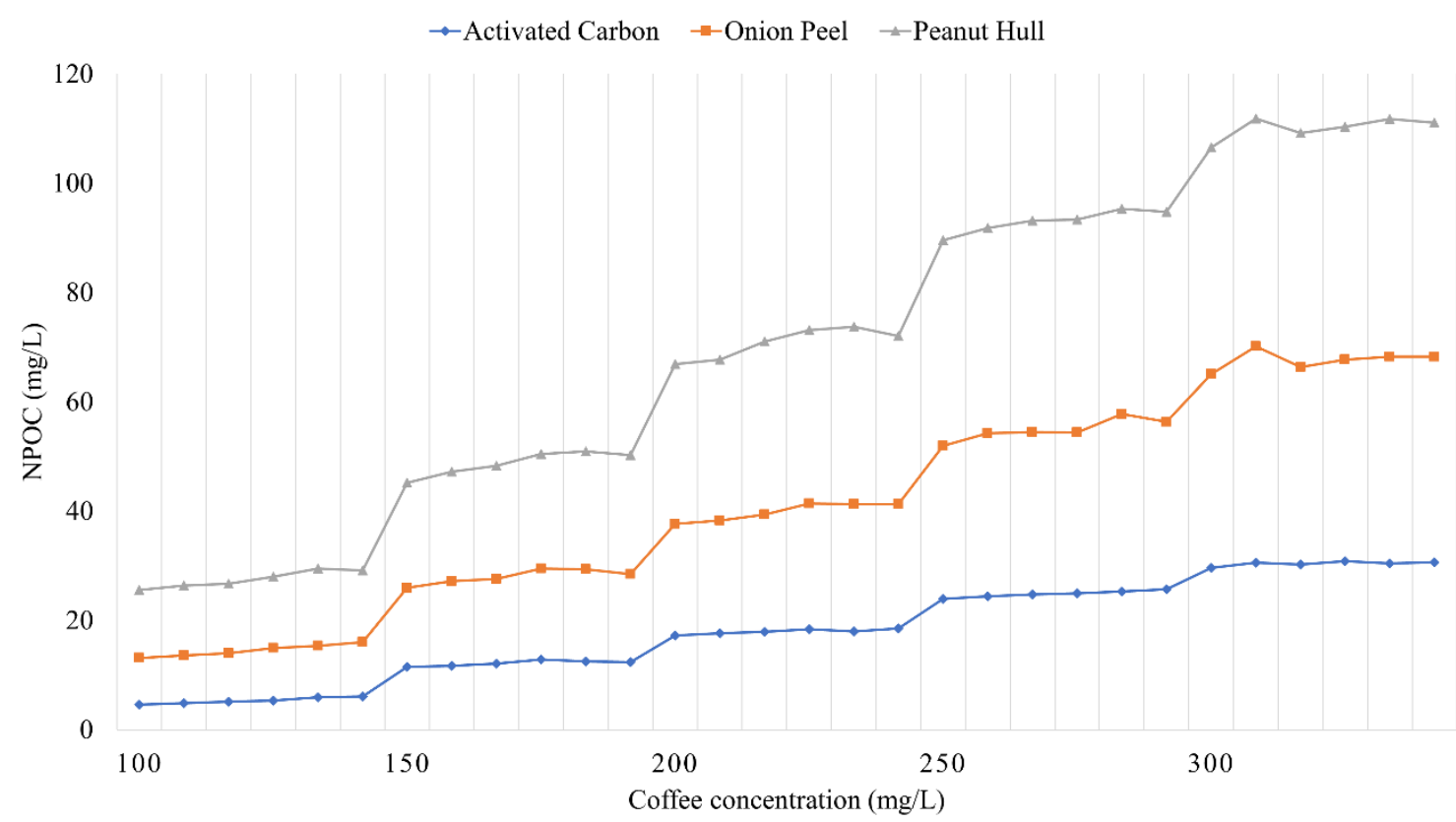

\section{Adsorption isotherm}

The Beer-Lambert law was used to find the final concentration of wastewater after treatment. The amount of dye adsorbed at the equilibrium can be calculated as follows:

$$
q_{e}=\frac{\left(C_{0}-C_{e}\right) V}{w}
$$

where $C_{0}$ is initial concentration $(\mathrm{mg} / \mathrm{L}), \mathrm{C}_{\mathrm{e}}$ is equilibrium concentration $(\mathrm{mg} / \mathrm{L})$, and $\mathrm{W}$ is weight of the adsorbent used (g).

The kinetics involved in the adsorption process of binary wastewater was investigated using two adsorption isotherms, mainly Langmuir and Freundlich isotherms. The equations involved in the isotherms are as follows:

$\frac{1}{\mathrm{q}_{\mathrm{e}}}=\frac{1}{\mathrm{~K}_{\mathrm{L}} \mathrm{Q}_{\mathrm{m}}} * \frac{1}{\mathrm{C}_{\mathrm{e}}}+\frac{1}{\mathrm{Q}_{\mathrm{m}}}$

(Langmuir isotherm equation) $\log \mathrm{q}_{\mathrm{e}}=\log \mathrm{K}_{\mathrm{f}}+\frac{1}{\mathrm{n}} \log \mathrm{C}_{\mathrm{e}}$

(Freundlich isotherm equation)

where $\mathrm{q}_{\mathrm{e}}$ is the amount of dye adsorbed at time $\mathrm{t}$ $(\mathrm{mg} / \mathrm{g}), K_{L}$ is the Langmuir adsorption coefficient, $Q_{m}$ is the maximum adsorption capacity $(\mathrm{mg} / \mathrm{g}), \mathrm{K}_{\mathrm{f}}$ is the Freundlich constant for adsorption capacity, and $\mathrm{n}$ is the Freundlich constant for intensity. The coefficients of the linearized form of both Langmuir and Freundlich isotherms were mentioned in Table 2 and Table 3. Only Langmuir isotherm seems to have a reasonable fit to the observed data using low-cost adsorbents, as shown in Table 2.

As we can see that the Freundlich constant was less than 1, which indicated the intercept was negative, which was highly unusual for a linear fit model. So, the Freundlich isotherm cannot fit the observed concentration uptake data of acid black 48 wastewater, combined with coffee wastewater, using low-cost adsorbents. Also, the $\mathrm{R}^{2}$ values were not close to 1 compared with Langmuir isotherm linear fit, as shown in Table 2. 
Table 2. Adsorption isotherms coefficients and capacity using low-cost adsorbents

\begin{tabular}{l|c|c|c|c|c|c|}
\hline \multirow{2}{*}{ Adsorbent } & \multicolumn{5}{|c|}{ Langmuir } & \multicolumn{3}{c}{ Freundlich } \\
\cline { 2 - 7 } & $Q_{m}(\mathrm{mg} / \mathrm{g})$ & $\mathrm{K}_{\mathrm{L}}(\mathrm{L} / \mathrm{mg})$ & $\mathrm{R}^{2}$ & $\mathrm{~K}_{\mathrm{f}}$ & $\mathrm{n}$ & 0.90 \\
\hline Peanut hull & 46.3 & 0.15 & 0.83 & 0.08 & 0.09 & 0.73 \\
\hline Onion peel & 58.1 & 0.17 & 0.82 & 1.04 & 0.09 \\
\hline
\end{tabular}

The maximum uptake for onion peel was $58.1(\mathrm{mg} / \mathrm{g})$, compared with the peanut hull being $46.3(\mathrm{mg} / \mathrm{g})$. This shows that onion peel has a better adsorption capacity than peanut hull. Based on plotting and comparing $R^{2}$ values, the best linear fit of equilibrium data with both Langmuir and Freundlich isotherms, using peanut hull and onion peel, were observed in the linearized plots from Fig. 7 to Fig. 10.

Absorbance and transmittance parameters used in the current study were obtained under controlled conditions at $25^{\circ} \mathrm{C}$ temperature in the laboratory. Also, wastewater samples were not exposed to atmospheric oxygen because of the possibility of getting oxidized. Further investigation based on sensitivity analysis with variable temperatures may improve the treatment efficiency. The results indicated that Langmuir isotherm was the best fit for peanut hull and onion peel in the adsorption process. Adsorbent uptake of $58.1 \mathrm{mg} / \mathrm{g}$ and $46.3 \mathrm{mg} / \mathrm{g}$ using onion peel and peanut hull, respectively, can be used to upscale the current treatment approach for full-scale application.

Fig. 7. Langmuir isotherm for acid black 48 adsorbed on peanut hull adsorbent

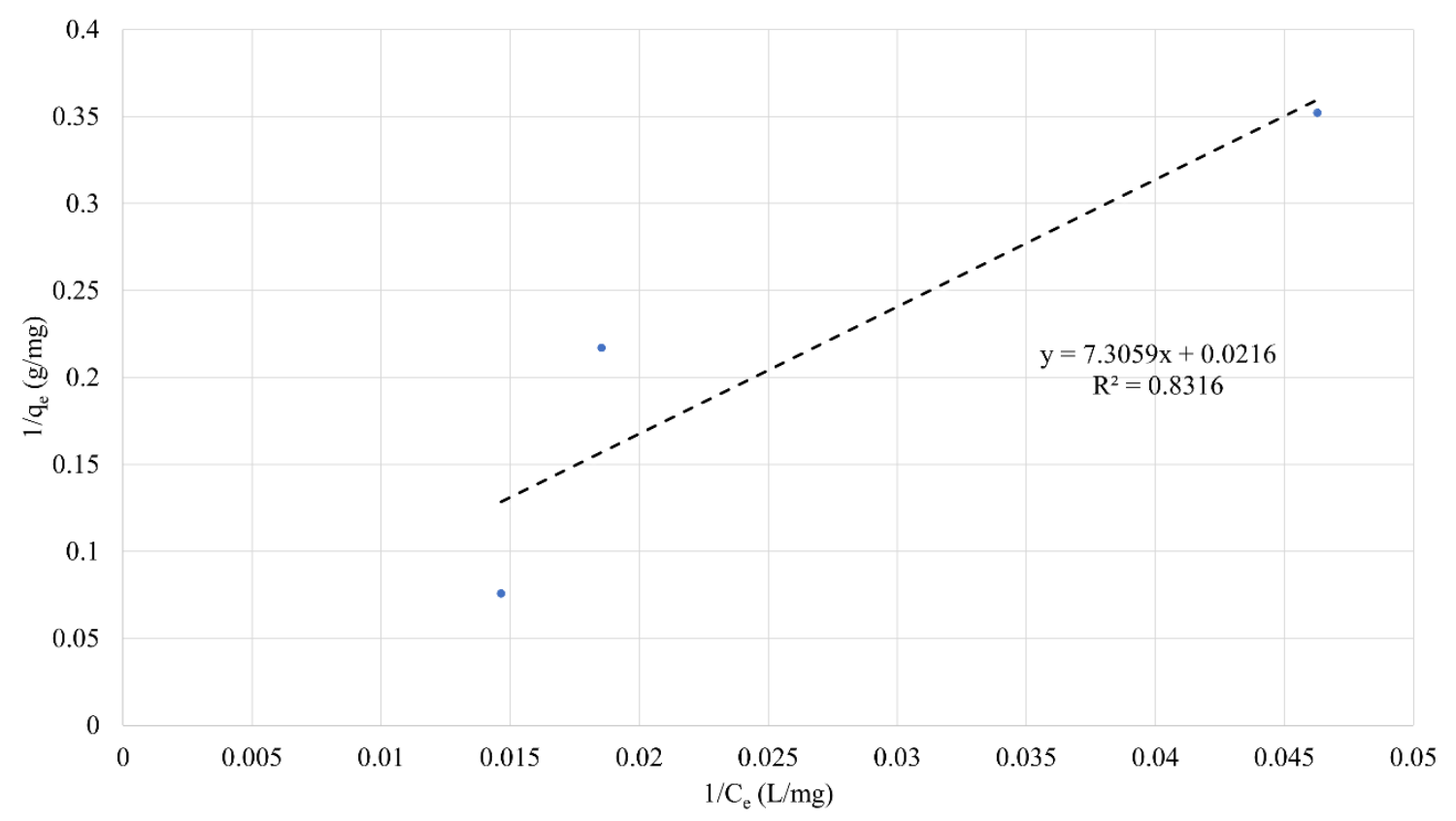


Fig. 8. Langmuir isotherm for acid black 48 adsorbed on onion peel adsorbent

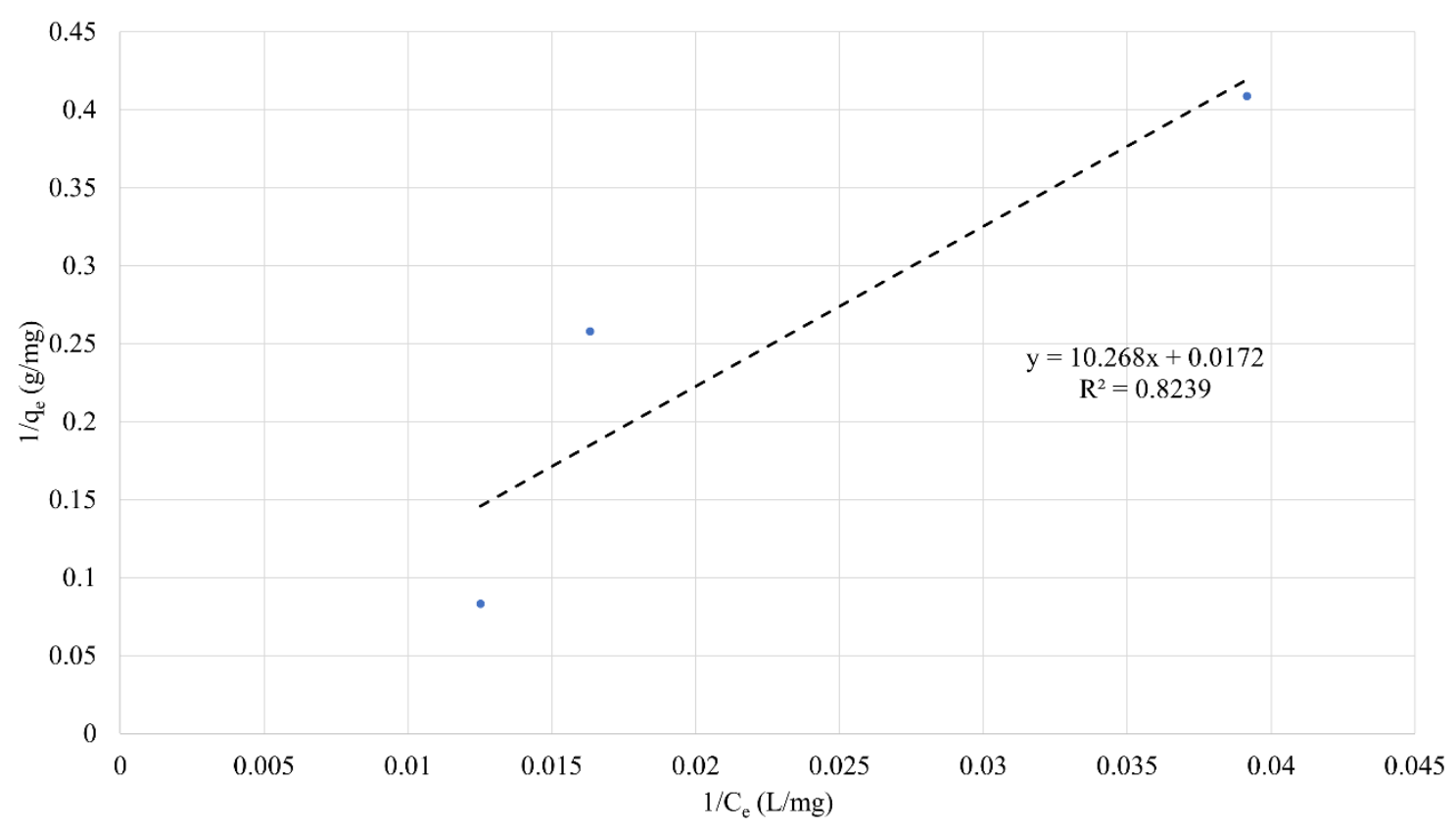

Fig. 9. Freundlich isotherm for acid black 48 adsorbed on peanut hull adsorbent

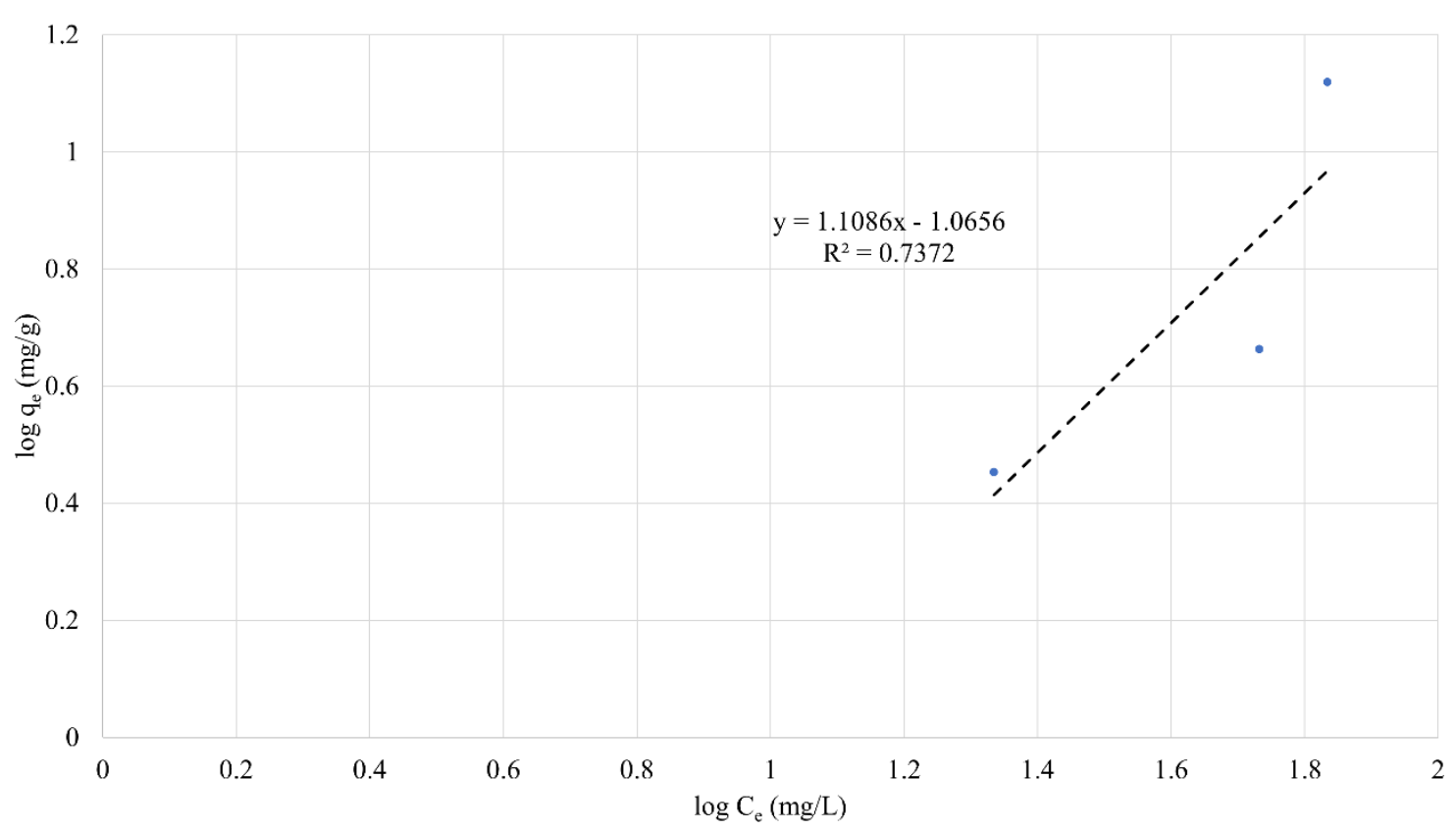


Fig. 10. Freundlich isotherm for acid black 48 adsorbed on onion peel adsorbent

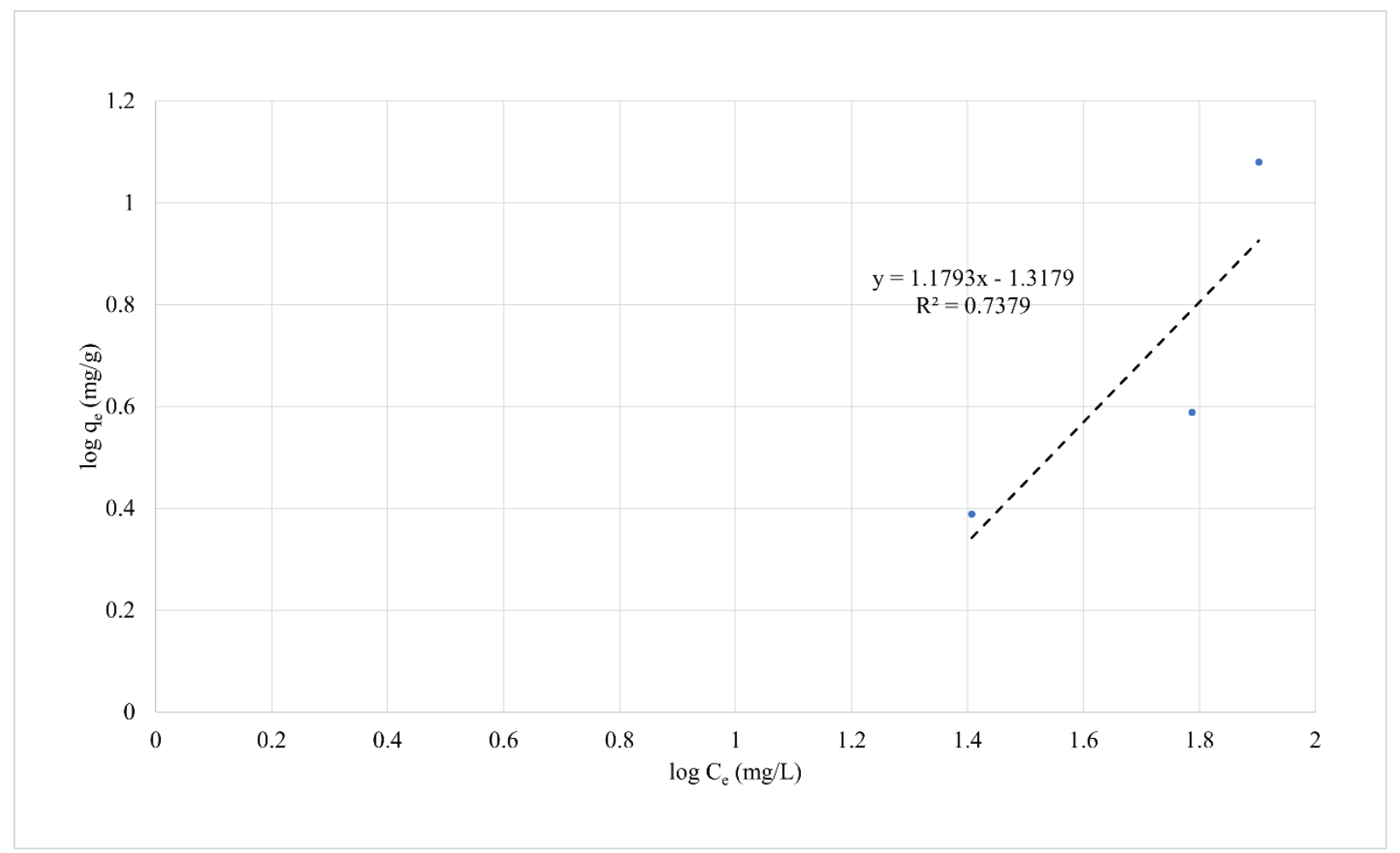

\section{Conclusions}

Transmittance is an important parameter that can estimate color removal from combined dye and coffee wastewater. Maximum transmittance in the treated sample indicates the highest treatment efficiency in removing color from the combined wastewater sample. Based on this study, it is found that both the adsorbents, including onion peel and peanut hull, have the potential to remove color in combined acid black 48 and coffee wastewater from aqueous solution. Onion peel can treat combined wastewater with a maximum transmittance of $80.1 \%$ and $75.6 \%$ at low and medium concentrations of combined wastewater. In comparison, peanut could achieve transmittance of $69.4 \%$ at high concentrations of combined acid black 48 and coffee wastewater. The optimum $\mathrm{pH}$ in the adsorption process for combined acid black 48 wastewater and coffee wastewater solution was found to be around 5.7. The isotherm study indicated that equilibrium sorption data is the best fit for Langmuir isotherm but not for Freundlich isotherm with an $\mathrm{R}^{2}$ value of 0.83 and 0.82 for peanut hull and onion peel, respectively. Modeled equations for the color removal of combined wastewater using peanut hull was $y=7.306 X+0.0216$ and using onion peel was $y=10.268 X+0.0172$. The higher slope with onion peel indicated better color removal, using onion peel as a low-cost adsorbent when compared with peanut hull. The maximum adsorption capacities estimated from both peanut hull and onion peel were $46.3 \mathrm{mg} / \mathrm{g}$ and $58.1 \mathrm{mg} / \mathrm{g}$, respectively.

\section{Acknowledgment}

The authors are grateful to the research facilities provided by Cleveland State University, Ohio, USA. 


\section{References}

Adegoke, K. A., and Bello, O. S. (2015). Dye sequestration using agricultural wastes as adsorbents. Water Resources and Industry, 12, 8-24. https://doi.org/10.1016/j.wri.2015.09.002

Ahmed, T. F., Sushil, M., and Krishna, M. (2012). Impact of dye industrial effluent on physicochemical characteristics of Kshipra River, Ujjain City, India. International Research Journal of Environmental Sciences, 1(2), 41-45.

Alhashimi, H. A., and Aktas, C. B. (2017). Life cycle environmental and economic performance of biochar compared with activated carbon: A meta-analysis. Resources, Conservation and Recycling, 118, 13-26. https://doi.org/10.1016/j.resconrec.2016.11.016

Andorn, M., and Bar-Eli, K. H. (1971). Optical Bleaching and Deviations from Beer-Lambert's Law of Solutions Illuminated by a Ruby Laser. I. Cryptocyanine Solutions. The Journal of Chemical Physics, 55(10), 5008-5017. https://doi.org/10.1063/1.1675614

Augugliaro, V., Prevot, A. B., Vázquez, J. C., Garcıa-López, E., Irico, A., Loddo, V., Rodriguez, S. M., Marcı, G., Palmisano, L., and Pramauro, E. (2004). Photocatalytic oxidation of acetonitrile in aqueous suspension of titanium dioxide irradiated by sunlight. Advances in Environmental Research, 8(3-4), 329-335. ttps:// doi.org/10.1016/S1093-0191(02)00106-5

Bekbölet, M., Lindner, M., Weichgrebe, D., and Bahnemann, D. (1996). Photocatalytic detoxification with the thin-film fixed-bed reactor (TFFBR): Clean-up of highly polluted landfill effluents using a novel TiO2-photocatalyst. Solar Energy, 56(5), 455-469. https://doi.org/10.1016/0038-092X(96)00020-5

Bharti, P. K., Kumar, P., and Singh, V. (2013). Impact of industrial effluents on ground water and soil quality in the vicinity of industrial area of Panipat city, India. Journal of Applied and Natural Science, 5(1), 132-136. https://doi.org/10.31018/jans. v5i1.294

Chen, C., Yang, J., and Findlay, C. (2008). Measuring the effect of food safety standards on China's agricultural exports. Review of World Economics, 144(1), 83-106. https://doi.org/10.1007/ s10290-008-0138-z

Chen, Z., Gao, L., Chen, C., and Butts, C. L. (2017). Analysis on technology status and development of peanut harvest mechanization of China and the United States. Trans. Chin. Soc. Agr. Mach., 48, 1-21.

Dey, S., and Islam, A. (2015). A review on textile wastewater characterization in Bangladesh. Resources and Environment, 5(1), 15-44.

Din, A. T. M., Hameed, B., and Ahmad, A. L. (2009). Batch adsorption of phenol onto physiochemical-activated coconut shell. Journal of Hazardous Materials, 161(2-3), 1522-1529. https://doi.org/10.1016/j.jhazmat.2008.05.009

Fletcher, S. M., and Shi, Z. (2016). An overview of world peanut markets. In Peanuts (pp. 267-287). Elsevier. https://doi. org/10.1016/B978-1-63067-038-2.00010-1

$\mathrm{Fu}, \mathrm{Y}$., and Viraraghavan, T. (2001). Fungal decolorization of dye wastewaters: A review. Bioresource Technology, 79(3), 251262. https://doi.org/10.1016/S0960-8524(01)00028-1

Ge, Q., Wang, P., Wan, C., and Chung, T.-S. (2012). Polyelectrolyte-promoted forward osmosis-membrane distillation (FOMD) hybrid process for dye wastewater treatment. Environmental Science and Technology, 46(11), 6236-6243. https://doi. org/10.1021/es300784h

Gummagolmath, K. (2012). Trends in marketing and export of onion in India. Research Report, National Institute of Agricultural Marketing, Jaipur.

Hameed, B., and Ahmad, A. (2009). Batch adsorption of methylene blue from aqueous solution by garlic peel, an agricultural waste biomass. Journal of Hazardous Materials, 164(2-3), 870875. https://doi.org/10.1016/j.jhazmat.2008.08.084

Hassaan, M. A., and Nemr, A. E. (2017). Health and Environmental Impacts of Dyes: Mini Review. https://doi.org/10.11648/j. ajese.20170103.11

Huang, T., Chiueh, P., and Lo, S. (2017). Life-cycle environmental and cost impacts of reusing fly ash. Resources, Conservation and Recycling, 123, 255-260. https://doi.org/10.1016/j.resconrec.2016.07.001

Imtiazuddin, S., Mumtaz, M., and Mallick, K. A. (2012). Pollutants of wastewater characteristics in textile industries. J Basic Appl Sci, 8, 554-556. https://doi.org/10.6000/19275129.2012.08.02.47

Islam, A., and Guha, A. K. (2013). Removal of pH, TDS and color from textile effluent by using coagulants and aquatic/non aquatic plants as adsorbents. Resources and Environment, 3(5), 101-114.

Johnson, P., Watson, M., Brown, J., and Jefcoat, I. (2002). Peanut hull pellets as a single use sorbent for the capture of $\mathrm{Cu}$ (II) from wastewater. Waste Management, 22(5), 471-480. https:// doi.org/10.1016/S0956-053X(01)00036-8

Kirkels, F. M. S. A., Cerli, C., Federherr, E., Gao, J., and Kalbitz, K. (2014). A novel high-temperature combustion based system for stable isotope analysis of dissolved organic carbon in aqueous samples. II: Optimization and assessment of analytical performance. Rapid Communications in Mass Spectrometry, 28(23), 2574-2586. https://doi.org/10.1002/rcm.7053 
Kornaros, M., and Lyberatos, G. (2006). Biological treatment of wastewaters from a dye manufacturing company using a trickling filter. Journal of Hazardous Materials, 136(1), 95-102. https://doi.org/10.1016/j.jhazmat.2005.11.018

Kosson, D. S., van der Sloot, H. A., Sanchez, F., and Garrabrants, A. C. (2002). An integrated framework for evaluating leaching in waste management and utilization of secondary materials. Environmental Engineering Science, 19(3), 159-204. https:// doi.org/10.1089/109287502760079188

Li, X., Jin, X., Zhao, N., Angelidaki, I., and Zhang, Y. (2017). Novel bio-electro-Fenton technology for azo dye wastewater treatment using microbial reverse-electrodialysis electrolysis cell. Bioresource Technology, 228, 322-329. https://doi. org/10.1016/j.biortech.2016.12.114

Limbachiya, M., Meddah, M. S., and Ouchagour, Y. (2012). Use of recycled concrete aggregate in fly-ash concrete. Construction and Building Materials, 27(1), 439-449. https://doi. org/10.1016/j.conbuildmat.2011.07.023

Lin, S. H., and Peng, C. F. (1996). Continuous treatment of textile wastewater by combined coagulation, electrochemical oxidation and activated sludge. Water Research, 30(3), 587-592. https://doi.org/10.1016/0043-1354(95)00210-3

Luengo, C., Brigante, M., Antelo, J., and Avena, M. (2006). Kinetics of phosphate adsorption on goethite: Comparing batch adsorption and ATR-IR measurements. Journal of Colloid and Interface Science, 300(2), 511-518. https://doi.org/10.1016/j. jcis.2006.04.015

Madiraju, S. V. H., Hung, Y.-T., and Paul, H. H. (2018a). Treatment of Acid Orange 74 Wastewater and Sugar Wastewater by Low Cost Adsorbents. Journal of Advanced Chemical Sciences, 583585. https://doi.org/10.30799/jacs.188.18040304

Madiraju, S. V. H., Hung, Y.-T., and Paul, H. H. (2018). Treatment of Disperse Blue 14 Wastewater and Sugar Wastewater By Low Cost Adsorbents.

Madiraju, S. V. H., Kumar, A., and Nishadhi, L. (2019). Examination of plant-based coagulants to replace lime and alum for surface water treatment. 10.
Madiraju, S. V. H., Raghunadh, P. G., and Kumar, K. R. (2020). Prototype of Eco-Friendly Indoor Air Purifier to Reduce Concentrations of $\mathrm{CO}$.

Okoronkwo, M. U., Balonis, M., Katz, L., Juenger, M., and Sant, G. (2018). A thermodynamics-based approach for examining the suitability of cementitious formulations for solidifying and stabilizing coal-combustion wastes. Journal of Environmental Management, 217, 278-287. https://doi.org/10.1016/j.jenvman.2018.02.095

Ong, S.-T., Khoo, E.-C., Hii, S.-L., and Ha, S.-T. (2010). Utilization of sugarcane bagasse for removal of basic dyes from aqueous environment in single and binary systems. Desalination and Water Treatment, 20(1-3), 86-95. https://doi.org/10.1080/194 43994.2010.10513772

Ren, N., Zhou, X., Guo, W., and Yang, S. (2013). A review on treatment methods of dye wastewater [J]. CIESC Journal, 1.

Robinson, T., McMullan, G., Marchant, R., and Nigam, P. (2001). Remediation of dyes in textile effluent: A critical review on current treatment technologies with a proposed alternative. Bioresource Technology, 77(3), 247-255. https://doi.org/10.1016/ S0960-8524(00)00080-8

Shon, Z.-H., Kim, K.-H., Jeon, E.-C., Kim, M.-Y., Kim, Y.-K., and Song, S.-K. (2005). Photochemistry of reduced sulfur compounds in a landfill environment. Atmospheric Environment, 39(26), 4803-4814. https://doi.org/10.1016/j.atmosenv.2005.06.024

Sultana, Z., Ali, M. E., Uddin, M. S., and Haque, M. M. (2013). Implementation of effluent treatment plants for waste water treatment. https://doi.org/10.4236/jep.2013.43035

Torretta, V., Ferronato, N., Katsoyiannis, I. A., Tolkou, A. K., and Airoldi, M. (2017). Novel and conventional technologies for landfill leachates treatment: A review. Sustainability, 9(1), 9. https:// doi.org/10.3390/su9010009

Weng, C.-H., and Pan, Y.-F. (2007). Adsorption of a cationic dye (methylene blue) onto spent activated clay. Journal of Hazardous Materials, 144(1), 355-362. https://doi.org/10.1016/j.jhazmat.2006.09.097

Yaseen, D. A., and Scholz, M. (2016). Shallow pond systems planted with Lemna minor treating azo dyes. Ecological Engineering, 94, 295-305. https://doi.org/10.1016/j.ecoleng.2016.05.081 